Paper accepted for submission to Special Issue (plus Special Section) of Qualitative Research in Psychology; Creative Representations of Qualitative Research

\title{
Madhouse and the Whole Thing There
}

\author{
Simon Paul Clarke ${ }^{1,2}$ \\ ${ }^{1}$ School of Education, University of Nottingham, Jubilee Campus, Wollaton Road, Nottingham \\ NG8 1BB, UK \\ ${ }^{2}$ Department of Psychology, Nottingham Trent University, 50 Shakespeare Street, Nottingham \\ NG1 4FQ, UK
}

Correspondence to:

Dr Simon Clarke,

Department of Psychology,

Chaucer 4019

Nottingham Trent University,

50 Shakespeare Street,

Nottingham

NG1 4FQ, UK

Tel: 0115848 4547;

Email: simon.clarke@nottingham.ac.uk; simon.clarke@ntu.ac.uk 


\begin{abstract}
This article presents an autoethnography in the form of a short story of the experiences of a mental breakdown, and subsequent involuntary detainment, alongside the experiences of conducting $\mathrm{PhD}$ research outside the mainstream of the discipline of psychology. In response to criticisms of narrative approaches that they are methodologically solipsistic and present a socially atomised self, this narrative combines patient medical records with narrative recollections, alongside reflections on the research process from a contemporary perspective. In doing so, the narrative explores and interrogates themes relevant to creative practice in psychological research including the notion of authenticity, methodological issues of researching personal experience, the problem of subjectivity and, ultimately, the nature of madness and psychological distress, including its non-linearity and otherness.
\end{abstract}

Keywords: autoethnography; creative practice; madness; mental health services; authenticity; subjectivity; survivor research

Word Count: 3,750 words 


\section{Prologue}

As a teenager, I had a psychotic breakdown and was involuntarily detained under the UK 1983 Mental Health Act. Much later, now recovered and working as a clinical psychologist in the UK National Health Service (NHS), I came across my notes on the online patient database system. Recovering the notes eventually led to beginning a PhD, whereby the clinical notes where used as part of an autoethnographic methodology. What follows is a narrative in short story format whereby my experiences of finding the notes and starting the $\mathrm{PhD}$ is juxtaposed alongside the description of the breakdown, from the perspective of both service user and the medical team (as represented by the medical notes).

The research involves experimentation with voice, sources and perspective, alongside the use of a non-linear narrative structure and poetry. These devices are deliberate strategies of disorientating the reader, based on a recognition that narratives of madness often cohere to conventional narrative formats (Wood, 2011a) and so result, in Stone's (2004) words, in "a disjunction between the content to be narrated and the possibilities inhering in conventional narrative forms" (p. 18). The narrative is organised into short sections according to three main perspectives: the contemporary narrator, represented by the first-person voice; a reconstruction of my teenage experiences of going mad, represented by the second person perspective; and, finally, my clinical notes, presented verbatim and represented by the third person voice. Changes in narrative accounts are denoted by ***.

At the end of the account, the second person voice breaks in poetry, the structure of which reflects the experience of dissolution, echoing to some degree Woods' (2011a) and Stone's (2004) points around the need for narrative form to 
better reflect the dissonant experience of madness. The piece concludes with an epilogue discussing the methodology and its controversies in more depth.

As a final note, all identifying information such as person and place names have been altered to maintain confidentiality.

\section{Madhouse and the Whole Thing There}

It is this deep blankness is the real thing strange.

The more things happen to you the more you can't

Tell or remember even what they were.

The contradictions cover such a range.

The talk would talk and go so far aslant.

You don't want madhouse and the whole thing there

William Empson (2000) 'Let it Go'

It's the usual routine in my job as a clinical psychologist in the UK National Health Service (NHS), first thing in the morning: drop my back and coat on the desk; exchange pleasantries with the few team members in this early ("another day, another dollar" intones the nursing assistant); turn on the computer; go to the kitchen to make a coffee; check emails (not so bad, but it is still 8am); open the patient data system; swipe my card in the card reader; pick up the to-do list.

First action: respond to the care co-coordinator's query from yesterday evening ("Simon, could you maybe see this really nice guy for therapy? I think he 
could really do with a chat"). I search for the client on the system. It barely even registers that the client has a vaguely similar name to mine.

Until, emblazoned on the screen, somewhere near the bottom of the returned searches my name, address and date of birth.

I stare at the screen for a few seconds in wry disbelief. I have been taken back for a moment.

You are waiting for your first ward round. Throughout the week the other patients in the day hospital have told you stories about this Dr Clint. They say he enjoys winding patients up. They tell you that the ward round is a ritual in humiliation. They also tell you stories of being raped and physically abused in the inpatient ward. All you can think about is the significance of Dr Clint's name and how this also fits together somehow. This is how it will happen, you think. Everything is building to this.

20.9.94 Team discussion:

Need to look into family dynamics

? Started abusing marijuana after death of grandfather Also note: maternal Grandfather major mental health problems?

I suddenly snap out of the spell, look around quickly to see if anyone's near me. The coast is clear. I return to the screen. I feel anxious. What else do they have on me? I am so tempted to open the record but I know I can't do that - this 'patient' is under a 
different directorate. Even though these are my notes, I will lose my job if I open a record of a patient not 'belonging' to me.

From the waiting room a cheerful nurse calls you in. She smiles pleasantly as she ushers you into a small room. The room is packed with people - at least seven or eight. You weren't expecting this many people. The meeting starts without delay and already you can barely keep it together. Two officious-looking middle-aged men in suits at the head (doctors you assume) ask you questions.

One of the doctors leads. What's the problem? What have been doing with yourself then, eh? How long since you finished college? When was that then? How did you do? I mean, what were your grades like? What's the plan for the future?

You are barely keeping it together. The fear is intense and overwhelming. You cannot tell a coherent narrative. You keep contradicting yourself. You become so anxious you can barely talk. The two psychiatrists smile and seem to throw each other knowing glances. It looks like cold amusement in their eyes. One of the nurses rolls her eyes - at you or at them? You don't know.

21.9.94 W.R. ${ }^{1}$ Dr Clint

Presentation

? Do you see yourself as having a psychotic problem

Just a little bit down

Had friends at school

\footnotetext{
${ }^{1}$ Ward Round
} 
GCSE's English, Literature, History

A-levels English and History but 2 fails "because of drugs and stuff" Left $6^{\text {th }}$ form summer 1992

College Autumn 92 - summer 93

A-levels $C$ for English and

D for sociology

Since then works in Eastfarthingham as a kitchen porter

Most of his friends unemployed

"I just feel lonely"

An idea occurs to me. What's on the other system? Old, paper clinical notes are archived on a separate system and my contact with the mental health service ended long before this system went online. I open the programme. Different password (of course) and I can't remember this one, so I need to reset. Quickly now, other team members are beginning to file in slowly. Yes, that's it, I'm in. I type Clarke, Simon. Several records, but sure enough, I am there. 404 pages of me. Fuck. 
You have had enough. You mutter something in a quiet, barely audible, mumble. You walk out. The other doctor (the quiet one) follows you out. You chat in a nearby room. The doctor asks you what's wrong (we were only asking you questions, he says).

The doctor asks you whether you will consider being an inpatient. The selfassurance in the doctor's blue-grey eyes seems to imply that the decision has already been made. You can't keep your eyes away from the figure of the dark, hulking Victorian asylum with the barred windows that shimmer in the afternoon sun through the window opposite you.

No, you tell the doctor, I don't want to be an inpatient.

walks out; when asked about the last ward round he said

"Dr Clint is too slick"

Interviewed by Dr Muster

"sad about being sad"

Interviewed on his own $=$ perplexed

thoughts disappeared

"mind goes blank"

me and other 
palinposia ${ }^{2}$ confirmed

thoughts about killing himself;

but not current

In the car, in the car park, outside the clinic. Privacy needed. I am on my mobile phone to the Data Protection Manager of the mental health service. Yes, that's right I say. No, I didn't open the record on the online system. Yes, I know I could lose my job if I did that. I wave nervously as a colleague walks past into the clinic with a client in tow. Yes, I say back to the Data Protection Manager, I was a patient in the 1990s and I now work here for the same mental health service. Yes, I recovered. You haven't come across this kind of a case before? A pause. OK. Well...how can I get hold of my notes then? I don't know what's on the system and I'm concerned that my colleagues could access them. A Subject Access Request? Yes, I would. Very much. Thanks.

Suddenly and inexplicably the quiet doctor leaves the room where you were talking. Was it something you said? You are not sure why the doctor has left the room and whether you should wait for him to come back. What happens now?

\footnotetext{
2 'Palinopsia' is a visual disturbance that causes images to persist to some extent even after their corresponding stimulus has left. Although these afterimages occur in persons with normal vision, they can be associated with a diagnosis of schizophrenia (see Gates, Stagno \& Gulledge. 1988)
} 
You open the door to the corridor and see the doctor running back to the ward round room. You don't know what to do. You are scared. Will they drag you into the ward with straightjackets? Is that what happens here?

Impressions: probable early stage of schizophrenia, Simon's presentation is quite worrying as he appears to be quite unpredictable Risk of serious self-harm

Plan:

- $\quad$ try on Trifluoperazine $10 \mathrm{mg}$ nocte ${ }^{3}$ concurrent with Procyclidine $5 \mathrm{mg}^{4}$

- Simon's parents need to be seen regardless of his refusal for further independent information and to share with them our worries

- May be sectionable if not attends regularly at Day Hospital and refuses inpatient treatment

The large package, a full ream worth of paper, sits with me on the passenger seat all the way home, as it were a person. When I get home, my wife is waiting for me. I carry the large package to my chest like a baby. It's here I tell her, dropping the fat package on the table. We unwrap it together. The A4 cardboard box that was inside the package sits on the table. Are you going to open it then? She asks. I'm not sure, I say. I then open the lid and start rifiling through the first few pages. God, there's so much of it, she says. Her fingers pull out one sheet from the pile - PATIENT

\footnotetext{
${ }^{3}$ Medical shorthand terminology for 'nocturnal', i.e. evening.

${ }^{4}$ Milligrams
} 
PROPERTY LIST. Tears well up in her eyes. It's like you were going into prison. You were just a kid. A kid scared out your mind.

I'm not ready to read it, I say. I don't think I can handle it. It was such a shit time. Could you put it back in the box? Maybe l'll look at it later.

There is a brief moment of hesitation before you walk out of the hospital. On the way out, you bump into an elderly patient who recognises you from the day hospital. The man asks if you are OK. I'm going to be an inpatient, you reply. The other man says nothing but swallows, then looks down. He seems to understand what this means.

The warm September sun is all encompassing. You are in despair. This is it now. All you have is this moment: the one, unfailing, unremitting sense of crushing despair, without hope of abatement or reprieve. It is final and it is total. You would kill yourself if that would make a difference, but you know that it won't.

Slowly, like aspirin dissolving in water, your consciousness dissolves.

\section{RECORD OF NURSING CARE AND PATIENT PROGRESS}

22.9.94. Phone call from Simon's mother this am. She is concerned about the sudden deterioration in Simon. Came home yesterday was very preoccupied. She talked about suggestion made by Dr Muster about admission as inpatient \& told mother he did not want to come as afraid he would be with people who are mad \& also older than him. He slept very little, pacing up and down and smoking over 60 cigarettes, but was still up at 7 am today. Early waking is an unusual occurrence for him, always having difficulties in this area. Since August she has seen an apparent 
change in him. Before this he would have strong opinions \& would express them well now he is very passive. He isolates himself from the rest of the family.

Mother would like to talk to a doctor.

I'm still not sure what I want to do, I tell my PhD supervisor. I think I know what I want my PhD to be about, but I am not sure how to do it. I want to look at psychosis and the experiences of using mental health services, but I don't think I want to use a conventional psychological approach.

What's wrong with a conventional psychology approach? He smiles wryly. He is, after all, a psychologist.

I don't know, I reply, conscious that I might be overstepping a boundary. It's just...I pause and take a breath. Psychology deals with what it calls empirical 'data'. Either quantitative or qualitative - it doesn't matter, the process is the same. There is something that you 'find' that is 'real' which is more 'real' than what you as a 'subject' might 'experience'. But the more you abstract from the experience, the less real it becomes. Psychology has many layers of this abstraction from the subject of experience - to responses from a questionnaire, to data in a data set, to results from a statistical inquiry. Or themes from an interview - also taken from experience, by a researcher, with their preconceptions and bias, filtered, extrapolated and ultimately fitted into a format consumable for an institutional process, that is often a million miles away from the original experience. Frank (2005) mentions this when he talks about the dangers of chopping up stories into data.

He smiles, and then laughs. So it's a question of authenticity then? I guess so. 
Why not do an autoethnography then? He says.

I'm not sure what that is, I reply.

It's a research method. You use your own experience as data.

Your head is on fire

Napalmed consciousness

Submerged undersea

Arm cold clay

Knife flashes red in early light

Four scarlet tracks

Like claws

'Blood sacrifice'

See? No

pain

['I am just a corpse']

11:00 hrs Simon did not come to the day hospital but his mother came. Seen jointly with Dr Quell. Mrs Clarke was sent home from work (district nurse) as she was too distressed. Simon was still at home, looking in a world of his own, not acknowledging her when she spoke to him. Afraid of coming into day hospital.

Mrs Clarke is obviously very distressed by the situation. She has been the support for Simon as Simon is not able or willing to talk to Father. Mother is very concerned about his unpredictability and lives in fear he might harm himself. 
She took him to see a male counsellor when he came off "DRugs", but Simon could not relate to him.

Admission offered.

What's wrong? Asks my wife, her furrowed brow blue in the reflected glare of her laptop screen over which she peers at me.

Nothing, I say. She throws me 'that look' over the brim of her computer.

I sigh. I've finished writing out my experiences and memories as bullet points. I now need to write them up as an autoethnography, as a narrative.

So what's the problem?

It's just...the one perspective seems to rule. I write my experiences down, but what does it matter? It's what I experienced and how I made it. So what? Who really gives a shit?

She shrugs. So look at other perspectives then. What about your notes? They might be really useful to look at, now you're writing your own experiences down. That's another perspective. How would that feel?

It's an interesting idea, I think.

Visions of men with dog heads and

demons, dragons and fire.

The trees are laughing faces, 
laughing at you.

The world kills and eats you

O the horror

All-consuming hatred

O the horror

Breathe breathe breathe

Please try to breathe, please try

The past returns

Generations of it

All of the horror of

The past

In you.

Is you.

22.9.94 Mother

Came last night

Very restless at home, smoking, drinking tea

$\downarrow$

This morning

Staring into space

Unwilling to come into hospital

Personality changed in Aug

Suddenly very fearful of changing same night 
Mother believes has not been the same for last year or so

\author{
Plan - Needs to come to D.H. ${ }^{5}$ this pm \\ - otherwise we will discuss with G.P. whether section is \\ indicated
}

But it's more than that, I tell my PhD supervisor. Narrative research reconstructs experience to fit a neat trajectory. All of the messiness is ironed out, all of the uncertainty, and confusion, and pain. The story is presented in a nice, neat linear way: beginning, middle, end. But's it's not like that. Not when you go crazy. Maybe not even when you're sane.

That's fair enough, he says. This is one of our first supervision sessions since I changed supervisors. He is a mental health nurse by background and not a psychologist. He likes creative approaches to these issues.

But how do I get this across? I press. How do I communicate that going mad is often not some extension of normal human processes, like Bentall (2003) and others argue, but is a radical movement into a different way of being, like Laing (1960) or Lacan (Leader, 2014) suggest?

My supervisor shrugs. Try experimenting he says. See where things go. Put different voices to the voices. Use different tenses. Sometimes that changes things.

\footnotetext{
${ }^{5}$ Day hospital
} 
You stand by the front porch facing the morning sun with a look of exultation. You have been transformed. The voices have gone along with the visions. The fear is no more. There are feelings of release. Your brothers walk past, unaware, it seems, of the transformation in you. You take a lighter to your t-shirt, watching the fabric dissolve in a flurry of sparks. You throw the flaming bundled ball that used to be a tshirt onto the front porch. The fire alarm squeals in protest. Your brother brushes past, quickly putting out the fire. He throws you a worried look. What the fuck, Si?

14:00 - Mother phoned. Has agreed to come in voluntarily to hospital. Had burnt shirts \& cigarettes? Scratches on limb.

For admission to A1

I sit at the same table as I sat three years' ago when I first collected my notes. My clinical notes are on the left, my hand written recollections of the same events on the right.

And that, I think, is the crux of the matter. Much narrative research in mental health is based on the first-person perspective only, which can, if unchecked, lead down the same back-alley of mainstream psychology in its stubborn refusal to jettison the atomised, individualised self.

The failure of such a self is its inability to acknowledge that we are inescapably and unutterably social, to our very core. Our experience is not our own. For good or for ill, we are what we are to the people who live with us, and who we 
love, and sometimes who we hate. We are the product of what other people make us to be, and what we make of them.

It's like Patty Lather (2009) argues, "authenticity is much more complicated than singular, transparent, static identity categories assumed to give the writer a particular view" (p. 20).

I think about the people involved in my story: the clinicians who detained me, with all of the best intentions I suspect, but which left me broken and traumatised for many years afterwards; my family, who suffered with me, helpless, but who also contributed, unconsciously and unknowingly, to my distress; my wife, who worked with me to get these experiences down on paper; the therapeutic community, who helped me get my life back; and, finally, my PhD supervisors who guided me and helped me to recognise and give voice to the different people and perspectives around me. My subjectivity is shared amongst them.

And yet... it is a wry irony, and a deep paradox, that, ultimately, the 'buck stops here': one person with a pen and a pad, trying to make sense of all of this complexity.

But I don't think about that too much just yet. I put pen to pad. I begin to write. You are waiting for your first ward round...

\section{END}

\section{Epilogue}

Autoethnography is a narrative methodology where the experiences of the researcher are use as the primary source of 'data'. I say 'data' but even this term is disputed amongst narrative researchers who argue, with Frank (2005), that 
quantitative researchers' usage of such terms implies "that the true value of the final report lies in the process of refining, finishing, and, one could even say, civilizing this raw material" (p. 90) rather than the lived experience itself, presented in its entirety (Woods, 2011b). Autoethnography arose out of the so-called 'narrative turn' or 'crisis of representation' where the assumptions and practices of the human and social sciences came under a sustained period of questioning (Wall, 2016). In the world of mental health research, autoethnographies from people with 'lived experience' of psychological distress became tied to emancipatory political movements such as the survivor/service user movement (Rose, 2017). In doing so, they attempted to give 'voice' to previously marginalised discourses against the appropriation of the experience of mental health survivors and service users in narrative research (Russo, 2016a).

As a research method, autoethnography remains controversial. Paul Atkinson (2009) argues that the voices of narrative are, "too often treated as sources of authenticity, grounded in the biographical particularities of speaking subjects" (2.11), whilst also lamenting autoethnographers' 'lack of nerve' in textual experimentation with social research (Atkinson, 2013). In the field of mental health, some writers caution against the dangers of 'disability tourism' in first-person perspective research (Costa et al., 2012). Others comment on the apparent contradiction between the use of terms such as 'lived experience' on the one hand, and the valorisation of poststructuralist theory on the other, which, to a lesser or greater extent, eschews the validity of those very same terms (Rose, 2017). In other words, emphasising 'lived experience' in a strategic way, whilst superficially attractive, can lead to an assumption of homogeneity in a field marked by complexity and difference (Voranka, 2016). Finally, other critiques, echoing Atkinson (2009), argue that first person 
approaches such as autoethnography continue to present a socially atomised and non-collectivised self that can frustrate effective political engagement (Rose, 2016).

This article depicted my attempt to respond to these critiques, whilst still maintaining a commitment to the use of first-person perspective research which, I believe, is an important form for communicating mad experiences. To this end, I employed a short-story format with three parallel narratives to portray the experience of madness from two perspectives (the clinicians and service user) and the process of developing these experiences into an autoethnography. In doing so, I was presenting a dialogical form of research that highlighted the socially-situated and unfinished nature of the self (Frank, 2005). The juxtaposition of medical team and service user perspectives served to highlight the contrast between personal and clinical accounts, thus highlighting important areas of difference in how mental health is treated (Voronka, 2016). By emphasising the second person voice in the service user perspective I was highlighting my commitment to the process of dialogue with the reader (see Russo, 2016b).

Ultimately, any attempt to represent the experience of extreme psychological distress is a difficult one in which there are no easy answers (Rose, 2017). The depiction of extremely distressing experiences need not, I believe, become a form of 'mental health porn' but can be a deliberate attempt to present an unfinished narrative "excessive and leaky but based in lack and ruin rather than plenitude" (Lather, 2009, p. 22). In other words, the authenticity is in the recognition that we can never really tell our own stories effectively, but yet, somehow, we are still disposed to try. Or, as Samuel Beckett (1983) wrote in Worstward ho, "Ever tried. Ever failed. No matter. Try again. Fail again. Fail better.” 


\section{References}

Atkinson, PA 2009, 'Illness narratives revisited: the failure of narrative reductionism', Sociological Research Online vol. 14, no. 5, viewed 4 September 2016, <http://www.socresonline.org.uk/14/5/16.html>.

Atkinson, PA 2013, 'Ethnographic writing, the avant-garde and a failure of nerve', International Review of Qualitative Research, Vol. 6, No. 1, pp. 19-35.

Bentall, R 2003, Madness Explained: Psychosis and Human Nature, Penguin, London.

Beckett, S 1983, Worstward ho, Calder, London.

Costa, L, Voronka, J, Landry, D, Reid, J, Mcfarlane, B, Reville, D \& Church, K 2012, ‘"Recovering our stories"': a small act of resistance', Studies in Social Justice, vol. 6 , no. 1 , pp. $85-101$.

Frank, A 2005, 'What is dialogical research, and why should we do it?', Qualitative Health Research, vol. 15, no. 7, pp. 964-974.

Laing, RD 1960, The Divided Self, Penguin, London

Leader, D 2014, What is Madness?, Penguin, London

Empson, W 2000, The Complete Poems (ed. John Haffenden), Allen Lane, Ann Arbor, MI

Lather, PA 2009, 'Against empathy, voice and authenticity', in AY Jackson \& LA Mazzei (eds.), Voice in Qualitative Inquiry: Challenging Conventional, Interpretive, and Critical Conceptions in Qualitative Research, Routledge, London, pp. 17-26.

Gates, TJ, Stagno, SJ, Gulledge, AD 1988, 'Palinopsia posing as a psychotic depression', The British Journal of Psychiatry, vol. 153, no. 3, pp. 391-393. 
Rose, D 2016, 'Experience, madness theory, and politics', Philosophy, Psychiatry, \& Psychology, vol. 23, no. 3, pp. 207-210.

Rose, D 2017, 'Service user/survivor-led research in mental health: epistemological possibilities', Disability \& Society, vol. 32, no. 6, pp. 773-789.

Russo, J 2016a, 'In dialogue with conventional narrative research in psychiatry and mental health', Philosophy, Psychiatry, \& Psychology, vol. 23 no. 3, pp. 215228.

Russo, J 2016b, 'Establishing first-person knowledge of madness: must this undertaking elide our differences?', Philosophy, Psychiatry, \& Psychology, vol. 23 no. 3 , pp. $237-240$.

Stone, B 2004, 'Towards a writing without power: notes on the narration of madness', Auto/Biography, vol. 12, pp. 16-33.

Voronka, J 2016, 'The politics of 'people with lived experience' Experiential authority and the risks of strategic essentialism', Philosophy, Psychiatry, \& Psychology, vol. 23 no. 3, pp. 189-201.

Wall, S 2016, 'Toward a moderate autoethnography', International Journal of Qualitative Methods, vol. 15, no. 1, pp. 1609-4069

Woods, A 2011a, 'Memoir and the diagnosis of schizophrenia: reflections on the centre cannot hold; me, myself, and them; and the 'crumbling twin pillars' of Kraepelinian Psychiatry', Mental Health Review, vol. 16, no. 3, pp. 102-106. Woods, A 2011b, 'The limits of narrative: provocations for the medical humanities', Medical Humanities, vol. 37, no. 2, pp. 73-78. 


\section{Author Biography:}

Simon Clarke has experience of madness and using mental health services, is a UK Health and Care Professions Council-registered clinical psychologist, and is currently working as a senior lecturer within the Department of Psychology at Nottingham Trent University. Simon qualified with his Doctorate in Clinical Psychology (DClinPsy) in 2009 from Salomons Centre for Applied Psychology at Tunbridge Wells. Following this, he worked in the UK National Health Service in early intervention in psychosis and then in chronic pain services. He also worked as a research clinical psychologist for the Arthritis Research UK Pain Centre at the University of Nottingham and as an academic tutor on the Trent Doctorate in Clinical Psychology training programme at the University of Lincoln. Simon is currently completing his $\mathrm{PhD}$ in authenticity and madness narratives in the School of Education at the University of Nottingham. 